\title{
A Single Seizure Episode Leads to Rapid Functional Activation of KCC2 in the Neonatal Rat Hippocampus
}

\author{
Stanislav Khirug, ${ }^{1 *}$ Faraz Ahmad, ${ }^{1 *}$ Martin Puskarjov, ${ }^{1}$ Ramil Afzalov, ${ }^{1}$ Kai Kaila, ${ }^{1,2}$ and Peter Blaesse ${ }^{1}$ \\ ${ }^{1}$ Department of Biosciences and ${ }^{2}$ Neuroscience Center, University of Helsinki, FI-00014 Helsinki, Finland
}

Functional expression of the $\mathrm{K}-\mathrm{Cl}$ cotransporter $\mathrm{KCC} 2$ in developing central neurons is crucial for the maturation of $\mathrm{Cl}^{-}$-dependent, $\mathrm{GABA}_{\mathrm{A}}$ receptor-mediated inhibitory responses. In pyramidal neurons of the rodent hippocampus, GABAergic postsynaptic responses are typically depolarizing and often excitatory during the first postnatal week. Here, we show that a single neonatal seizure episode induced by kainate injection during postnatal days 5-7 results in a fast increase in the $\mathrm{Cl}^{-}$extrusion capacity of rat hippocampal CA1 neurons, with a consequent hyperpolarizing shift of the reversal potential of $\mathrm{GABA}_{\mathrm{A}}$-mediated currents $\left(\mathrm{E}_{\mathrm{GABA}}\right)$. A significant increase in the surface expression of KCC2 as well as the $\alpha 2$ subunit of the Na-K-ATPase parallels the seizure-induced increase in the $\mathrm{Cl}^{-}$extrusion capacity. Exposing hippocampal slices to kainate resulted in a similar increase in the neuronal $\mathrm{Cl}^{-}$extrusion and in the surface expression of KCC2. Both effects were blocked by the kinase inhibitor K252a. Hence, in the neonatal hippocampus the overall KCC2 expression level is high enough to promote a rapid functional activation of $\mathrm{K}-\mathrm{Cl}$ cotransport and a consequent negative shift in $\mathrm{E}_{\mathrm{GABA}}$ close to the adult level. The activity-dependent regulation of KCC2 function and its effect on GABAergic transmission may represent an intrinsic antiepileptogenic mechanism.

\section{Introduction}

A number of studies on native neocortical and hippocampal neurons have shown a close correlation between the maturation of hyperpolarizing GABAergic inhibition and the expression of the neuron-specific $\mathrm{K}-\mathrm{Cl}$ cotransporter $\mathrm{KCC} 2$ in the postsynaptic neurons (Ben-Ari et al., 2007; De Koninck, 2007; Kahle et al., 2008; Blaesse et al., 2009). In an analogous manner, depolarizing shifts in $\mathrm{E}_{\mathrm{GABA}}$ that take place during neuronal epilepsy and trauma have been associated with a decrease in the total amount of KCC2 protein (e.g., Khalilov et al., 2003; Rivera et al., 2004; Munoz et al., 2007, Huberfeld et al., 2007; Glykys et al., 2009). In view of the widely recognized but poorly understood differences in neonatal and adult epilepsies (Moshe and Galanopoulou, 2002; Ben Ari and Holmes, 2006; Rennie and Boylan, 2007), it is intriguing that recurrent seizures at postnatal day $(\mathrm{P}) 4-6$ lead to a precocious hyperpolarizing $\mathrm{E}_{\mathrm{GABA}}$ shift in $\mathrm{CA1}$ pyramidal neurons of male rats 3-5 d after seizure induction, paralleled by an increase in KCC2 expression (Galanopoulou, 2008). A similar effect was recently observed after enriched environment rearing (He et al., 2010).

In addition to transcriptional regulation of KCC2, posttranslational changes in KCC2 functionality have been demonstrated to set the time course of the development of hyperpolarizing

Received June 18, 2010; accepted July 13, 2010.

This study was supported by grants from the Academy of Finland, the Sigrid Jusélius Foundation, and the Jane and Aatos Erkko Foundation (K.K.). K.K. is a member of the Finnish Center of Excellence in Molecular and Integrative Neuroscience Research. We are grateful to Dr. Jon Bragi Bjarnason for providing the cod trypsin. We thank Dr. Leonard Khirug for assistance in experimental work and for helpful discussions, and Anton Tokariev (MSc) for the quantitative analysis of field recordings.

*S.K. and F.A. contributed equally to this work.

Correspondence should be addressed to Professor Kai Kaila, Department of Biosciences, University of Helsinki, Fl-00014 Helsinki, Finland. E-mail: Kai.Kaila@Helsinki.Fi.

DOI:10.1523/JNEUROSCI.3154-10.2010

Copyright $\odot 2010$ the authors $\quad$ 0270-6474/10/3012028-08\$15.00/0 inhibition in auditory brainstem structures (Balakrishnan et al., 2003; Blaesse et al., 2006). Fast posttranslational changes in KCC2 functionality have been demonstrated under in vitro and in vivo conditions (e.g., Khirug et al., 2005; Fiumelli et al., 2005; Lee et al., 2007; Hewitt et al., 2009). Data of this kind show that the functionality of KCC2 can be strongly affected by nontranscriptional mechanisms.

In the present work, we have examined the effects of neonatal seizures on KCC2 functionality within a time window spanning from tens of minutes to hours. Using electrophysiological as well as biochemical techniques, we show that a single seizure episode in vivo as well as a brief period of seizure-like activity in vitro triggers a fast activation of $\mathrm{Cl}^{-}$extrusion in hippocampal CA1 neurons of P5-7 rats. While the total protein expression level of KCC2 remains unchanged, the increase in the $\mathrm{Cl}^{-}$extrusion efficacy is associated with an increase in the plasmalemmal fraction of $\mathrm{KCC} 2$, and results in a large negative shift in $\mathrm{E}_{\mathrm{GABA}}$ that attains a level that is comparable to what is seen in CA1 pyramidal neurons after the developmental $\mathrm{E}_{\mathrm{GABA}}$ shift under control conditions (Khirug et al., 2005). The enhancement in the efficacy of GABAergic inhibition might act as an intrinsic antiepileptogenic mechanism in the neonate brain.

\section{Materials and Methods}

Experiments were approved by the local Animal Ethics Committee of the University of Helsinki and by the Ethics Committee of the National Laboratory Animal Center Finland.

Preparation and maintenance of slices. Hippocampal slices from P5-7 and P16 rats were used. The animals were anesthetized with pentobarbital, and $600 \mu \mathrm{m}$ horizontal or $400 \mu \mathrm{m}$ coronal brain slices were cut using a Vibratome 3000 (Vibratome). Slices were bathed in standard physiological solution containing the following (in $\mathrm{mm}$ ): $124 \mathrm{NaCl}, 3 \mathrm{KCl}, 2$ $\mathrm{CaCl}_{2}, 25 \mathrm{NaHCO}_{3}, 1.1 \mathrm{NaH}_{2} \mathrm{PO}_{4}, 2 \mathrm{MgSO}_{4}$, and 10 D-glucose, equili- 
brated with $95 \% \mathrm{O}_{2}$ and $5 \% \mathrm{CO}_{2}$, pH 7.4 at the experimental temperature of $32^{\circ} \mathrm{C}$. The slices were allowed to recover at $36^{\circ} \mathrm{C}$ for $1 \mathrm{~h}$ before the experiments were started.

Induction of neonatal seizures. Seizures were induced in male P5-7 rat pups (Wistar) with a single intraperitoneal injection of kainate $(2 \mathrm{mg} / \mathrm{kg}$ body weight; Tocris Bioscience). Saline injections were performed as controls. Rats were injected in pairs, with a $1 \mathrm{~h}$ interval between the littermates and a randomized order of saline and kainate injections. Behavioral seizures progressed from an initial stage of immobility, followed by bouts of scratching behavior, hyperactivity, ataxia, and isolated myoclonic jerks, into tonic or tonic-clonic seizures without recovery. Continuous behavioral monitoring was performed by video recording to define the onset of seizures (the initial stage of immobility), which took place $31.5 \pm 2.2 \mathrm{~min}$ after kainate injection. Hippocampal slices were prepared after a $1 \mathrm{~h}$ seizure period. Slices from saline-injected rats were prepared $1.5 \mathrm{~h}$ after the injection.

Induction of seizure-like activity in vitro. Seizure-like activity was induced by a $10 \mathrm{~min}$ incubation of horizontal hippocampal slices $(600 \mu \mathrm{m})$ in $300 \mathrm{~nm}$ kainate in physiological solution as follows (in mM): $124 \mathrm{NaCl}$, $4 \mathrm{KCl}, 1.3 \mathrm{CaCl}_{2}, 25 \mathrm{NaHCO}_{3}, 1.1 \mathrm{NaH}_{2} \mathrm{PO}_{4}, 1.3 \mathrm{MgSO}_{4}$, and 10 D-glucose, equilibrated with $95 \% \mathrm{O}_{2}$ and $5 \% \mathrm{CO}_{2}$, pH 7.4 at the experimental temperature of $32^{\circ} \mathrm{C}$. After $10 \mathrm{~min}$, the slices were transferred to the physiological solution with $1 \mu \mathrm{M}$ TTX (Tocris Bioscience) added to block neuronal activity and $10 \mu \mathrm{M}$ bumetanide to block the $\mathrm{Na}-\mathrm{K}-2 \mathrm{Cl}$ cotransporter NKCC1. In biochemical experiments, a 5 min kainate application followed by a 5 min washout with physiological solution was repeated up to six times. Some slices were pre-exposed to $200 \mathrm{~nm} \mathrm{K252a}$ for $30 \mathrm{~min}$ before exposure to kainate plus K252a.

Electrophysiological recordings. Preparation of hippocampal slices from P5-7 and P16 rat pups and electrophysiological recordings (whole-cell, gramicidin-perforated patch, and field-potential recordings) were performed as described before (Khirug et al., 2005, 2008; Sipilä et al., 2009). In brief, gramicidin-perforated patch-clamp recordings were obtained using an EPC 10 amplifier (HEKA Elektronik). The patch pipette solution contained the following (in mM): $42 \mathrm{KCl}, 87 \mathrm{~K}$-gluconate, $0.5 \mathrm{CaCl}_{2}$, $2 \mathrm{NaOH}, 10$ glucose, 10 HEPES, $2 \mathrm{Mg}-\mathrm{ATP}$, and 5 BAPTA, $\mathrm{pH}$ adjusted to 7.3 with $\mathrm{KOH}$, and $100 \mu \mathrm{g} / \mathrm{ml}$ gramicidin $\mathrm{ABCD}$ (Sigma). Gramicidin was dissolved from a fresh dimethylsulfoxide stock solution $(100 \mathrm{mg} / \mathrm{ml})$ and sonicated just before each experiment. Patch pipettes were fabricated from borosilicate glass (Harvard Apparatus), and their resistance ranged from 4.5 to $6.5 \mathrm{M} \Omega$. Slices were positioned in a submerged-type recording chamber (volume, $\sim 1 \mathrm{ml}$ ). During the experiments, the chamber was continuously perfused at a rate of $1 \mathrm{ml} / \mathrm{min}$ with standard physiological solution containing TTX $(1 \mu \mathrm{M})$, CNQX $(10 \mu \mathrm{M})$, and AP5 $(40 \mu \mathrm{M})$ to block $\mathrm{Na}^{+}$-dependent action potentials and ionotropic glutamate receptors. Within 20-30 min after gigaseal formation, the access resistance dropped and stabilized at 40-100 $\mathrm{M} \Omega$. The voltage-clamp data were corrected off-line for series resistance. The potential difference across the perforated patch is 0 or $4.2 \mathrm{mV}$ when using $140 \mathrm{~mm} \mathrm{~K}$-gluconate or 140 $\mathrm{mm} \mathrm{KCl}$ in the pipette, respectively (Kim and Trussell, 2007). With the present composition of the pipette solution (see above), the potential across the perforated patch is $1-2 \mathrm{mV}$, which is small, compared with the calculated liquid junction potential of $-10.3 \mathrm{mV}$ (Barry, 1994). Therefore, the measured voltage-clamp data were corrected for liquid junction potential only. In the whole-cell patch-clamp recordings, the composition of the patch pipette solution was as follows (in $\mathrm{mm}$ ): $18 \mathrm{KCl}, 111$ K-gluconate, $0.5 \mathrm{CaCl}_{2}, 2 \mathrm{NaOH}, 10$ glucose, $10 \mathrm{HEPES}$, and $2 \mathrm{Mg}$-ATP, 5 BAPTA, and $\mathrm{pH}$ was adjusted to 7.3 with $\mathrm{KOH}$. Slices were perfused with standard physiological solution containing TTX $(1 \mu \mathrm{M})$ and bumetanide $(10 \mu \mathrm{M})$ to block $\mathrm{Na}^{+}$-dependent action potentials and NKCC1, respectively. The resistance of the patch pipettes was 5.5-6.5 M $\Omega$. The membrane potential values were corrected for a calculated liquid junction potential of $-10 \mathrm{mV}$. GABA was photolyzed from CNB-caged GABA (Invitrogen) using local uncaging as described previously (Khirug et al., 2005, 2008). Caged GABA (2.5 mM) was dissolved in the standard physiological solution and delivered at a flow rate of $1 \mu \mathrm{l} / \mathrm{min}$ to the vicinity of the patch-clamped cell using an UltraMicroPump II syringe pump (WPI) and a syringe with an inner tip diameter of $100 \mu \mathrm{m}$. For local photolysis of caged GABA, the $375 \mathrm{~nm}$ output of a continuous emission diode laser (Excelsior 375, Spectra-Physics) was delivered to the slice through an Olympus LUMPlanFl $60 \times$ water-immersion objective. The uncaging spot (diameter, $\sim 10 \mu \mathrm{m}$ ) was focused either at the soma or dendrite at a distance of $50 \mu \mathrm{m}$ from the soma. At each location, the current-voltage relationship was determined by varying the holding potential in a range from -90 to $-20 \mathrm{mV}$ (six steps of $10 \mathrm{mV}$ ). Voltage was stepped $200 \mathrm{~ms}$ before each photolysis event and held for $600 \mathrm{~ms}$. The $\mathrm{E}_{\mathrm{GABA}}$ gradient $\left(\Delta \mathrm{E}_{\mathrm{GABA}}\right)$ was defined as the difference of the values recorded at the dendrite and at the soma. For field-potential recordings, slices were kept in physiological solution as follows (in mM): $124 \mathrm{NaCl}, 4$ $\mathrm{KCl}, 1.3 \mathrm{CaCl}_{2}, 25 \mathrm{NaHCO}_{3}, 1.1 \mathrm{NaH}_{2} \mathrm{PO}_{4}, 1.3 \mathrm{MgSO}_{4}$, and $10 \mathrm{D}$-glucose, equilibrated with $95 \% \mathrm{O}_{2}$ and $5 \% \mathrm{CO}_{2}, \mathrm{pH} 7.4$ at the experimental temperature of $32^{\circ} \mathrm{C}$, and perfusion rate of $3.5 \mathrm{ml} / \mathrm{min}$. In some experiments with K252a, field potential activity was quantified within two frequency bands $(4-25 \mathrm{~Hz}$ and $25-100 \mathrm{~Hz})$ by calculating the cumulative rootmean square (RMS) of the extracellular signal for a $30 \mathrm{~min}$ epoch (cf. Ruusuvuori et al., 2004).

Immunoblot analysis. Proteins were separated by SDS-PAGE. Gel loading was performed in SDS-PAGE sample buffer containing $80 \mathrm{~mm}$ Tris- $\mathrm{HCl}, 2 \%$ SDS, $10 \%$ glycerol, $5.3 \% \beta$-mercaptoethanol, and $2 \%$ bromophenol blue. After electrophoretic separation, proteins were electrophoretically transferred to nitrocellulose membranes (PerkinElmer) in transfer buffer containing $25 \mathrm{~mm}$ Tris, $192 \mathrm{~mm}$ glycine, and 10\% methanol, pH 8.3. Membranes were blocked in TBST/milk (20 mm Tris, $150 \mathrm{~mm} \mathrm{NaCl}$, 0.1\% Tween-20, 5\% nonfat dry milk, $\mathrm{pH}$ 7.5) for $1 \mathrm{~h}$ at room temperature. Incubation with the respective antiserum diluted in TBST/milk was performed overnight in the refrigerator with agitation. Rabbit-anti-panKCC2 (1:1000; raised against amino acid residues 929-1045 of rat KCC2) (Ludwig et al., 2003) was used for KCC2; rabbit-anti-KCC2a (1:1000; raised against amino acid residues 2040) (DPESRRHSVADPRRLPREDVK) of rat KCC2a (Uvarov et al., 2009); rabbit-anti-KCC2b (1:1000; raised against amino acid residues 8-22) (CEDGDGGANPGDGNP) of rat KCC2b (Hübner et al., 2001); rabbitanti-Na-K-ATPase $\alpha 2$ (1:1000; Millipore, catalog \#AB9094); rabbit-antitubulin (1:20,000; Nordic BioSite, catalog \#PRB-435P) for the neuronal class III $\beta$-tubulin; and mouse-anti-transferrin receptor (TfR) (1:200; Zymed, catalog \#13-6800) for the transferrin receptor. An affinitypurified version of the anti-panKCC2 antibody (1:5000) was used in some experiments. After three washes in TBST, the secondary antibody, donkey anti-rabbit IgG horseradish peroxidase-conjugated (1:3000; GE Healthcare) or goat anti-mouse IgG horseradish peroxidase-conjugated (1:3000; Dako), was applied for 2-4 h at room temperature in TBST/milk with agitation. After three washes in TBST, bound antibodies were detected using an enhanced chemiluminescence kit (Pierce) and an LAS-3000 documentation system (Fujifilm). The conditions used ensured that KCC2 immunoreactivity was mainly present as a band with a molecular weight of $\sim 135 \mathrm{kDa}$ (Blaesse et al., 2006; Uvarov et al., 2009). Quantification of the chemoluminescence signals was performed by Advanced Image Data Analysis imaging software (Raytest). All measurements were within the linear range of the sensitivity of the camera. After quantification, the representative images included in the figures were optimized for brightness and contrast using Paint Shop Pro X (Corel).

Surface biotinylation. Hippocampal slices isolated from control and postseizure rats were labeled with $100 \mu \mathrm{M}$ biotin (Biotinamidohexanoyl-6-aminohexanoic acid N-hydroxysuccinimide ester; Sigma) in standard physiological solution on ice for $60 \mathrm{~min}$. The reaction was quenched by washing the slices with $1 \mathrm{~m}$ glycine in standard physiological solution for $10 \mathrm{~min}$ on ice. The CA1 region was isolated and subsequently homogenized in RIPA buffer ( $150 \mathrm{~mm} \mathrm{NaCl}, 1 \%$ Triton X-100, $0.5 \%$ deoxycholic acid, $0.1 \%$ SDS, $50 \mathrm{~mm}$ Tris-Cl, $\mathrm{pH}$ 8.0) with a protease inhibitor mixture (Complete Mini EDTA free protease inhibitor mixture; Roche), and the biotinylated proteins were purified on immobilized streptavidin agarose (Sigma) and eluted in SDS-PAGE sample buffer at $75^{\circ} \mathrm{C}$ for $10 \mathrm{~min}$. The eluent from the streptavidin column (biotinylated proteins) and the supernatant (unlabeled internal proteins) were separated on an $8 \%$ acrylamide gel, and the immunoblot analysis was performed as described above. For the surface analyses after induction of seizure-like activity in vitro, pairs of slice samples were processed in par- 
allel. First, the effect of seizure-like activity on KCC2 surface expression was analyzed and then the effect of K252a on this was assessed in separate experiments (i.e., control vs kainate and kainate vs kainate plus K252a). To compare the three experimental groups, the KCC2 immunoreactivity was normalized to the signal in the samples from the kainate group.

Trypsin cleavage of surface proteins. A protease approach to analyze the surface expression of KCC2 was modified from published protocols (Hall and Soderling, 1997; Grosshans et al., 2002) and based on cod trypsin (Zymetech), which retains its activity at low temperatures $\left(4^{\circ} \mathrm{C}\right)$. Coronal hippocampal slices $(400 \mu \mathrm{m})$ from control and postseizure rats were treated with cod trypsin $(4 \mu \mathrm{U} / \mathrm{ml}$ in standard physiological solution) on ice for $60 \mathrm{~min}$. After a wash step (10 min in standard physiological solution on ice), the hippocampal slices were homogenized, $30 \mu \mathrm{g}$ of protein was separated on a $6 \%$ acrylamide gel, and the immunoblot analysis was performed as described above.

Statistical analyses and curve fitting were performed using Origin software (Microcal). Data are presented as mean \pm SEM, and quantitative comparisons were based on Student's $t$ test, the Wilcoxon matched pairs test, or the nonparametric unpaired Kolmogorov-Smirnov test. Only significant differences $(p<0.05)$ between the different groups are indicated in the figures.

\section{Results}

\section{A single kainate-induced seizure episode leads to a negative shift in $\mathrm{E}_{\mathrm{GABA}}$}

A single intraperitoneal injection of kainate $(2 \mathrm{mg} / \mathrm{kg})$ in $\mathrm{P} 5-7$ rats resulted in behavioral seizures that were similar to those described before (Galanopoulou, 2008). One hour after seizure onset, hippocampal slices were prepared and taken for electrophysiological experiments. Gramicidin perforated patch recordings showed that the somatic $\mathrm{E}_{\mathrm{GABA}}$ in CA1 neurons from the control (saline-injected) rats was $-56.3 \pm$ $3.2 \mathrm{mV}$ (Fig. 1) ( $n=16$ neurons, 9 slices, 9 animals). Notably, in neurons from animals that had experienced the kainate-induced seizure, $\mathrm{E}_{\mathrm{GABA}}$ was much more negative, $-66.4 \pm 1.5 \mathrm{mV}(n=14$ neurons, 8 slices, 7 animals; $p=0.003)$, which is close to the values measured in naive animals at P16 $(-70.2 \pm 1.0 \mathrm{mV}$; $n=9$ neurons, 6 slices, 5 animals; $p=0.063)$.

Next, we tested whether the single seizure episode leads to a native somatodendritic $\mathrm{E}_{\mathrm{GABA}}$ gradient (in gramicidin-perforated patch recordings) of the kind that has recently been demonstrated in cortical neurons that have undergone the developmental $\mathrm{E}_{\mathrm{GABA}}$ shift (Khirug et al., 2008). Under control conditions, the dendritic $\mathrm{E}_{\mathrm{GABA}}$ of the P5-7 neurons was slightly depolarized compared with the somatic $\mathrm{E}_{\mathrm{GABA}}$ resulting in a very shallow native somatodendritic $\mathrm{E}_{\mathrm{GABA}}$ gradient $\left(\Delta \mathrm{E}_{\mathrm{GABA}}\right)$ of $0.26 \pm 0.02$ $\mathrm{mV} / 50 \mu \mathrm{m}$ (Fig. $1 C)(n=13$ neurons, 9 slices, 9 animals). In contrast, a substantial native $\Delta \mathrm{E}_{\mathrm{GABA}}$ with hyperpolarized responses in the dendrite was recorded in the CA1 neurons in postseizure slices $(-1.6 \pm 0.4 \mathrm{mV} / 50 \mu \mathrm{m} ; n=11$ neurons, 7 slices, 6 animals; $p=0.003)$. The native postseizure $\Delta \mathrm{E}_{\mathrm{GABA}}$ was similar
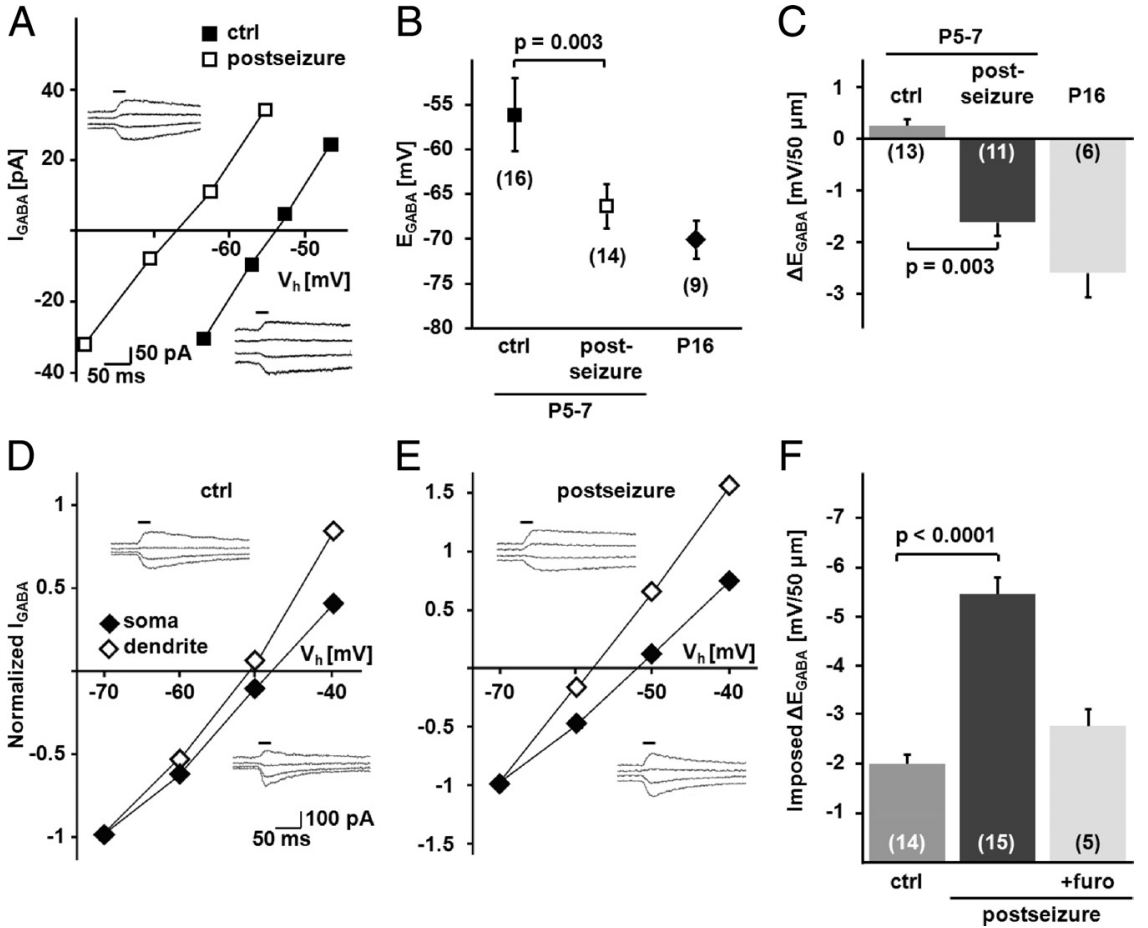

Figure 1. A single neonatal seizure episode leads to a negative shift in $\mathrm{E}_{\mathrm{GABA}}$ and activates a furosemide-sensitive $\mathrm{Cl}^{-}$ and a native somatodendritic $\mathrm{E}_{\mathrm{GABA}}$ gradient $\left(\Delta \mathrm{E}_{\mathrm{GABA}}\right)$ in $\mathrm{CA} 1$ neurons after a single kainate-induced seizure episode. $\boldsymbol{A}$ Sample $-V$ curves based on uncaging-induced $\mathrm{GABA}_{\mathrm{A}}$-mediated currents $\left(\mathrm{I}_{\mathrm{GABA}}\right)$ at different holding potentials $\left(\mathrm{V}_{\mathrm{h}}\right.$; origina

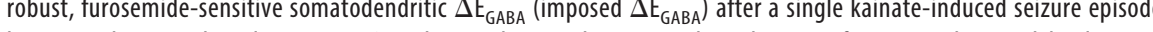
d $\Delta \mathrm{E}_{\mathrm{GABA}}$ value in the presence of $1 \mathrm{~mm}$ furosemide was not statistically different from the imposed $\Delta \mathrm{E}_{\mathrm{GABA}}$ under control conditions $(p=0.074)$. The values for $n$ are shown in brackets.

to the native $\Delta \mathrm{E}_{\mathrm{GABA}}$ present in $\mathrm{CA} 1$ neurons in slices from naive P16 rats $(-2.6 \pm 0.7 \mathrm{mV} / 50 \mu \mathrm{m} ; n=6$ neurons, 5 slices, 4 animals; $p=0.54)$.

Shifts in the native $\mathrm{E}_{\mathrm{GABA}}$ and $\Delta \mathrm{E}_{\mathrm{GABA}}$ can be attributable to changes in the efficacy of $\mathrm{Cl}^{-}$extrusion by KCC2 and/or $\mathrm{Cl}^{-}$ uptake by the $\mathrm{Na}-\mathrm{K}-2 \mathrm{Cl}$ cotransporter NKCC1. A significant depolarizing contribution of NKCC1 to the native somatic $\mathrm{E}_{\mathrm{GABA}}$ has been demonstrated in CA3 neurons at P2-4 using $10 \mu \mathrm{M}$ bumetanide, a selective blocker of NKCC1 at low concentrations (Russell, 2000), in gramicidin patch-clamp recordings combined with GABA uncaging (Sipilä et al., 2006, 2009). Using gramicidin patch-clamp recordings in combination with electrical stimulation, a similar bumetanide effect has been described for CA1 pyramidal cells at P9-14 (Galanopoulou, 2008). In the present study, bumetanide induced only a small negative shift in the native somatic $\mathrm{E}_{\mathrm{GABA}}$ of control CA1 neurons, which remained significantly more depolarized than the postseizure $\mathrm{E}_{\mathrm{GABA}}(-58.8 \pm 4.0 \mathrm{mV} ; n=5$ neurons, 3 slices, 3 animals; $p=0.95$ and 0.009 , respectively, when compared with control and postseizure neurons). In line with this, bumetanide did not induce any change in the native somatodendritic $\mathrm{E}_{\mathrm{GABA}}$ 


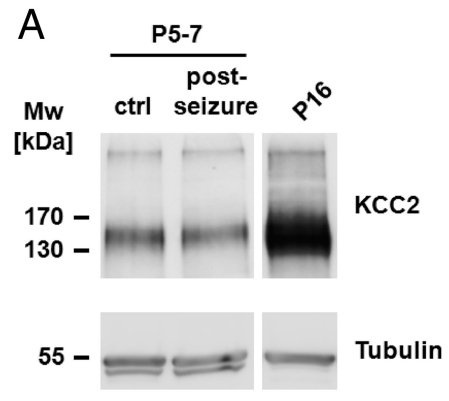

E Biotinylated fraction

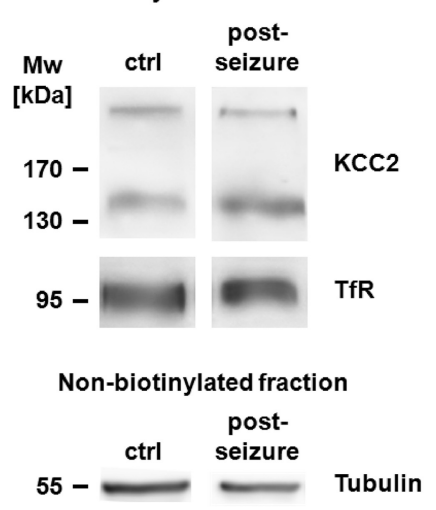

B



C

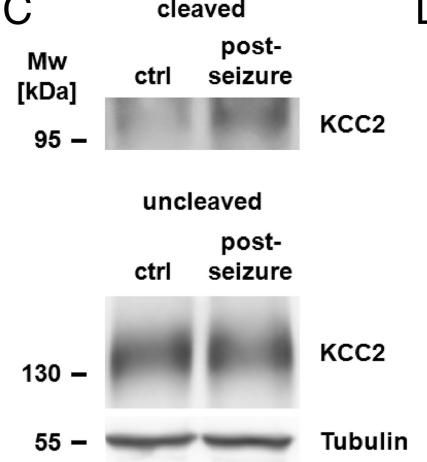

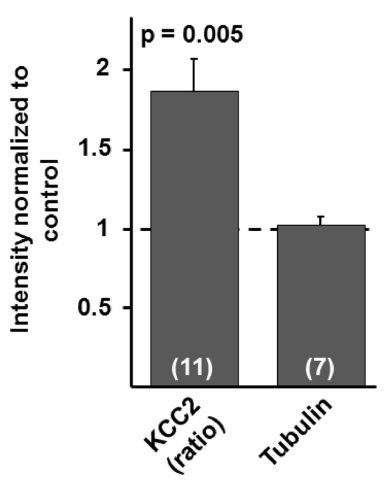

F

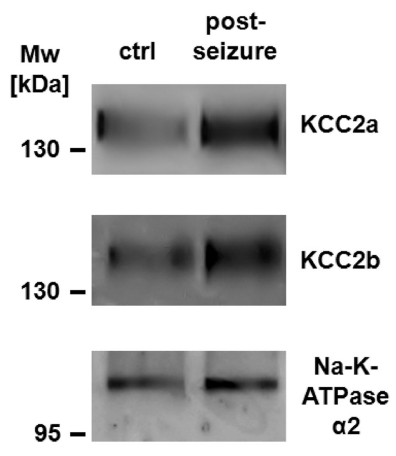

G

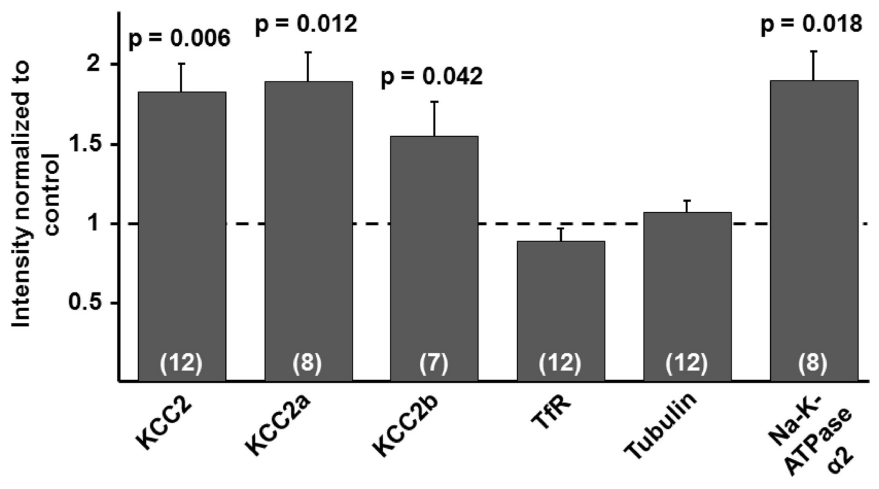

Figure 2. KCC2 surface expression, but not the total protein level, increases after a single neonatal seizure episode in vivo. $\boldsymbol{A}, \boldsymbol{B}$, The increase in the $\mathrm{Cl}^{-}$extrusion capacity did not correlate with an increase in the KCC2 protein level. The KCC2-immunoreactivity (IR) was quantified and normalized in immunoblots with protein samples of CA1 regions isolated from pairs of control (ctrl) and kainate-injected (postseizure) P5-7 rats. The KCC2 protein level after the seizure episode did not differ significantly from the level in control rats ( $p=0.44$ ). For comparison, a protein sample from a P16 rat was loaded on the gel. The $\beta$-tubulin signal confirmed that similar protein amounts were loaded. $\boldsymbol{C}, \boldsymbol{D}$, Protease treatment of hippocampal slices with trypsin demonstrated higher levels of cleaved KCC2 (surface pool) in CA1 samples from postseizure rats. $D$, The surface/intracellular ratio of KCC2 and the tubulin-IR in kainate-injected rats was normalized to the respective value in controls. While the tubulin-IR remained stable $(1.01 \pm 0.05, p=0.92)$, the $K C(2$ surface/intracellular ratio was 1.86 -fold higher after the seizure episode $(p=0.005)$. $\boldsymbol{E}-\boldsymbol{G}$, Biotinylation experiments showed an almost twofold increase in the KCC2 surface expression in the P5-7 postseizure CA1 area. $\boldsymbol{E}$, The KCC2-IR in the biotinylated fraction (surface proteins) was increased after kainate injections. The intensity of the TfR-IR in the biotinylated fraction and the tubulin-IR in the nonbiotinylated fraction (intracellular proteins) were not affected by the seizure episode. $\boldsymbol{F}$, The IR of KCC2 (panKCC2 antibody), KCC2a, KCC2b, TfR, tubulin, and the Na-K-ATPase subunit $\alpha 2$ in CA1 samples from kainate-injected rats were normalized to the respective IR in controls. The KCC2 surface expression was significantly higher after the seizure episode $(p=0.006)$. Postseizure slices showed an increased surface expression of the splice variants KCC2 $\mathrm{a}$ and $\mathrm{KCC} 2 \mathrm{~b}(1.87 \pm 0.19, p=0.012$ and $1.56 \pm 0.21, p=0.042$, respectively). The surface expression of TfR and the intracellular tubulin-signal remained unchanged ( $0.87 \pm 0.08, p=0.33$ and $1.07 \pm 0.07, p=0.86$, respectively). The surface expression of the Na-K-ATPase subunit $\alpha 2$ was increased by a factor of $1.89 \pm 0.18(p=0.018)$. The values for $n$ are shown in brackets. Statistical significance was assessed by the Wilcoxon matched pairs test.

gradient in control neurons $(0.009 \pm 0.03 \mathrm{mV} / 50 \mu \mathrm{m} ; n=4$ neurons, 4 slices, 2 animals; $p=0.44$ and 0.047 , respectively, when compared with control and to postseizure neurons). These data indicate that activation of KCC2 is responsible for the hyperpolarized $\mathrm{E}_{\mathrm{GABA}}$ and the establishment of the native $\Delta \mathrm{E}_{\mathrm{GABA}}$ in CA1 neurons in postseizure slices.

Seizure activity in vivo enhances the efficacy of neuronal $\mathrm{Cl}^{-}$ extrusion in neonatal neurons

To gain a quantitative estimate of the seizure-induced increase in the efficacy of $\mathrm{Cl}^{-}$extrusion, we used an assay where a constant somatic $\mathrm{Cl}^{-}$load is imposed on the neuron via a whole-cell patch pipette (containing $19 \mathrm{mM} \mathrm{Cl}^{-}$). As explained in detail previously (Khirug et al., 2005; Blaesse et al., 2009), the steepness of the ensuing somatodendritic $\Delta \mathrm{E}_{\mathrm{GABA}}$ (which is different from the native steady-state $\Delta \mathrm{E}_{\mathrm{GABA}}$ described above) provides a quantitative estimate of the efficacy of $\mathrm{Cl}^{-}$extrusion. In agreement with previous measurements in early postnatal pyramidal neurons (Khirug et al., 2005), uncaging of GABA at the soma and dendrite demonstrated the absence of an efficient $\mathrm{Cl}^{-}$extrusion in control CA1 neurons at P5-7, yielding an imposed $\Delta \mathrm{E}_{\mathrm{GABA}}$ of only
$-1.95 \pm 0.20 \mathrm{mV} / 50 \mu \mathrm{m}$ ( $n=14$ neurons, 7 slices, 2 animals $)$. In contrast, a steep imposed $\Delta \mathrm{E}_{\mathrm{GABA}}$ of $-5.28 \pm 0.35 \mathrm{mV} / 50 \mu \mathrm{m}$ ( $n=15$ neurons, 8 slices, 6 animals) was seen in neurons recorded in slices taken from postseizure animals $(p<0.0001)$ (Fig. $1 D-F)$. The increase in the imposed $\Delta \mathrm{E}_{\mathrm{GABA}}$ was abolished by 1 mM furosemide $(-2.70 \pm 0.34 \mathrm{mV} / 50 \mu \mathrm{m} ; n=5$ neurons, 3 slices, 2 animals; $p=0.0009$ when compared with postseizure neurons) (Fig. 1 F), a well established blocker of K-Cl cotransporters (Payne, 1997; Russell, 2000).

Seizure activity in vivo leads to an increase in the surface expression of $\mathrm{KCC} 2$

We studied whether the increase in the neuronal $\mathrm{Cl}^{-}$extrusion capacity is associated with an increase in total KCC2 protein expression as measured in immunoblots from hippocampal CA1 tissue (Fig. 2A, B). As shown before (Blaesse et al., 2006; Sipilä et al., 2009), the intensity of the KCC2 band in immunoblots at P5-7 was very low when compared with P16 (Fig. 2A). Notably, the total KCC2 level in the CA1 region of $\mathrm{P} 5-7$ rats that had experienced the kainate-induced seizure did not differ from controls (Fig. 2B) (0.92 \pm 0.10 when normalized to 
control; $n=11$ samples from 4 pairs of saline- and kainateinjected animals; $p=0.44$ ).

The efficacy of $\mathrm{Cl}^{-}$extrusion is set by the number of functionally active KCC2 molecules in the cell membrane, and changes in KCC2 trafficking have, indeed, been shown to contribute to the functional regulation of KCC2 (Lee et al., 2007; Wake et al., 2007). Therefore, we asked whether a kainate-induced seizure episode enhances the surface expression of KCC2. We first treated slices from postseizure and control hippocampi with trypsin, an approach that has been used to analyze the surface expression of glutamate receptors (Hall and Soderling, 1997; Grosshans et al., 2002). The amount of cleaved KCC2 in the isolated CA1 (i.e., KCC2 expressed on the plasma membrane and accessible to the protease) was significantly higher in postseizure samples (Fig. $2 C, D$ ). The protease approach allows the detection of the cleaved (surface) and uncleaved (intracellular) protein within one lane of a gel, and hence enables calculating the surface/intracellular KCC2 ratio in each sample. The mean ratio increased by a factor of $1.86 \pm 0.20$ in the postseizure CA1 ( $n=11$ samples from 4 pairs of saline- and kainate-injected animals; $p=0.005)$. In agreement with this, biotinylation experiments showed a significant postseizure increase in the KCC2 signal in the biotinylated fraction $(1.82 \pm 0.17 ; n=12$ samples from 7 pairs of saline- and kainate-injected animals; $p=$ 0.006 ) (Fig. 2E-G). Two splice variants of KCC2 (KCC2a and b) have recently been described (Uvarov et al., 2007). These isoforms are coexpressed in most brain regions and seem to be able to form heterodimers (Uvarov et al., 2009). Interestingly, biotinylation experiments with isoform-specific antibodies revealed similar seizure-induced changes in the CA1 surface expression of the two isoforms (1.87- and 1.56-fold increase for KCC2 a and KCC2b, with $n=8$ and $n=7$ samples from 6 and 5 pairs of saline- and kainate-injected animals, respectively) (Fig. $2 F, G$ ).

As a secondary-active transporter, KCC2 relies on the $\mathrm{K}^{+}$ gradient generated by the Na-K-ATPase, and it has been demonstrated that KCC2 interacts physically and functionally with the $\alpha 2$ subunit of the Na-K-ATPase (Ikeda et al., 2004). Notably, the surface expression of the $\alpha 2$ subunit in the CA1 was also increased after a neonatal seizure episode $(1.89 \pm 0.18 ; n=8$ samples from 7 pairs of saline- and kainate-injected animals; $p=$ 0.018 ) (Fig. $2 F, G$ ). The intracellular protein $\beta$-tubulin and the plasma membrane TfR served as controls to examine whether the seizure paradigm affected the integrity of the cells, which would lead to an unspecific increase in the biotinylation or cleavage of proteins. The data indicate that the kainateinduced seizure did not affect the control proteins $(n=12$ samples from 7 pairs of saline- and kainate-injected animals in biotinylation experiments, and $n=7$ samples from 4 pairs of kainate- and saline-injected animals) (Fig. 2). Together, the biochemical data show that the in vivo seizure episode resulted in an approximately twofold increase in the plasmalemmal pool of both KCC2 isoforms and of the $\alpha 2$ subunit of the Na-K-ATPase in the CA1 region.

\section{Seizure-like activity in vitro leads to a fast increase in neuronal $\mathrm{Cl}^{-}$extrusion}

To further investigate the time course and the mechanism underlying the seizure-induced KCC2 activation, we made experiments where slices were pre-exposed to $300 \mathrm{~nm}$ kainate to induce seizure-like activity (Fig. 3A). Similar to the results of the ex vivo approach, a $10 \mathrm{~min}$ period of kainate-induced activity led to a pronounced activation of $\mathrm{Cl}^{-}$extrusion (Fig. 3B-E) as demon- strated in the somatic $\mathrm{Cl}^{-}$load assay as an increase in the imposed $\Delta \mathrm{E}_{\mathrm{GABA}}$ from $-1.96 \pm 0.51 \mathrm{mV} / 50 \mu \mathrm{m}$ to $-6.04 \pm 0.52$ $\mathrm{mV} / 50 \mu \mathrm{m}$ (Fig. $3 E$ ) (control: $n=9$ neurons, 6 slices, 3 animals; post-kainate injection: $n=7$ neurons, 6 slices, 3 animals; $p<$ $0.0001)$. Figure $3 D$ shows that the effect is fast and progressive as it starts with a delay of $<30 \mathrm{~min}$ from the onset of kainate application. Control experiments showed that the imposed $\Delta \mathrm{E}_{\mathrm{GABA}}$ remained unaffected when slices were pre-exposed to kainate in the presence of $1 \mu \mathrm{M}$ TTX (Fig. $3 D, E)(-1.71 \pm 0.33 \mathrm{mV} / 50 \mu \mathrm{m}$; $n=7$ neurons, 4 slices, 2 animals; $p=0.70$ when compared with control), demonstrating that the enhanced activity (and not kainate as such) activates KCC2. In agreement with the results from the in vivo experiments, the increase in the imposed $\Delta \mathrm{E}_{\mathrm{GABA}}$ induced by seizure-like activity was blocked by $1 \mathrm{~mm}$ furosemide (Fig. $3 E)(-2.01 \pm 0.20 \mathrm{mV} / 50 \mu \mathrm{m} ; n=5$ neurons, 2 slices, 2 animals; $p=0.95$ when compared with control).

\section{The effect of seizure-like activity on neuronal $\mathrm{Cl}^{-}$extrusion and KCC2 surface expression is blocked by the kinase inhibitor K252a}

The similar time course and amplitude of the activity-induced changes in $\mathrm{Cl}^{-}$extrusion in the in vivo and in vitro models (Figs. 1,3 ) suggest that the effects seen in both models are based on similar mechanisms. To test whether a change in the surface expression of KCC2 similar to the one observed after a seizure episode in vivo (Fig. 2) occurs also in our in vitro model, we made biotinylation experiments with slices pre-exposed to $300 \mathrm{~nm}$ kainate. Indeed, the surface expression of KCC2 in the CA1 region after seizure-like activity in vitro was higher than in control slices (Fig. $3 F, G)(n=7$ pairs of control and post-kainate slice samples from 5 animals; $p=0.046$ ).

Interestingly, the increase in the $\mathrm{Cl}^{-}$extrusion capacity as well as the increase in the surface expression of KCC2 was abolished by $\mathrm{K} 252 \mathrm{a}$, a routinely used blocker of the tyrosine receptor kinase TrkB (Lee and Chao, 2001). First, we tested whether K252a (200 nM) affects the kainate-induced seizure-like activity. As shown in Figure $3 A$, seizure-like activity was present in slices exposed to kainate in the continuous presence of $\mathrm{K} 252 \mathrm{a}$ after preincubation in K252a for $30 \mathrm{~min}$. Moreover, the absence of a significant effect of K252a on seizure-like activity was further confirmed by offline measurements of the cumulative RMS in field-potential recordings, which did not differ in the low-frequency $(4-25 \mathrm{~Hz})$ or high-frequency $(25-100 \mathrm{~Hz})$ range between post-kainate and post-kainate plus K252a slices (normalized values $1.00 \pm 0.13$ $0.82 \pm 0.14$, and $1.0 \pm 0.06-0.96 \pm 0.10$, with $p=0.373$ and $p=0.747$, respectively; $n=5$ pairs of slices from 3 animals). Strikingly, the imposed $\Delta \mathrm{E}_{\mathrm{GABA}}$ in the presence of $\mathrm{K} 252 \mathrm{a}$ was only $2.6 \pm 0.30 \mathrm{mV} / 50 \mu \mathrm{m}$ ( $n=9$ neurons, 6 slices, 4 animals $)$, which is significantly lower than the imposed $\Delta \mathrm{E}_{\mathrm{GABA}}$ in neurons from slices pre-exposed to kainate $(p<0.001)$, but not different from the control value $(p=0.296)$. Similarly, the surface expression of KCC2 differed significantly between CA1 regions of slices preexposed to kainate and those of slices pre-exposed to kainate in the presence of $\mathrm{K} 252 \mathrm{a}$ with a mean ratio of $2.36 \pm 0.34(n=7$ pairs of slices from 4 animals; $p=0.028$ ).

In cell culture systems, $\mathrm{PKC}$ activation leads to a decrease in the KCC2 endocytosis rate and to a functional activation of the transporter (Lee et al., 2007). To investigate whether a change in the endocytosis rate of KCC2 can affect the function of the transporter in P5-7 CA1 pyramidal neurons, we added the dynamin inhibitory peptide (DIP; $50 \mu \mathrm{M}$ ), a commonly used endocytosis blocker (Wigge and McMahon, 1998), to the patch pipette solution in our somatic $\mathrm{Cl}^{-}$load gradient assay. The imposed 
A

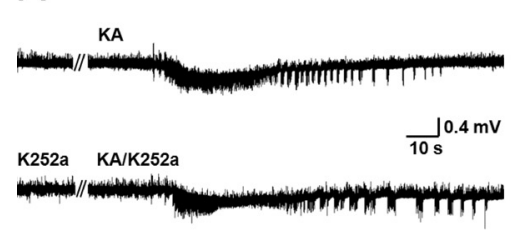

D



$\mathrm{F}$

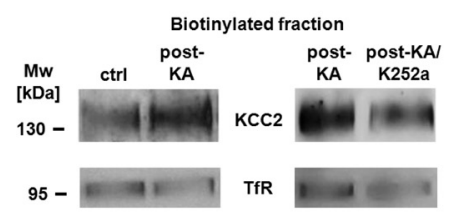

B

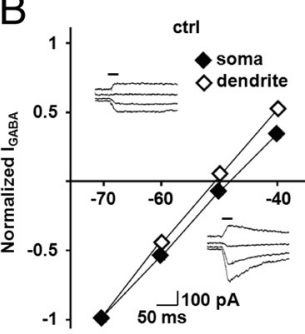

E

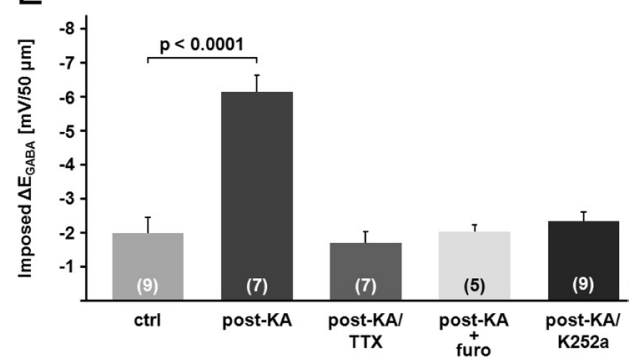

G

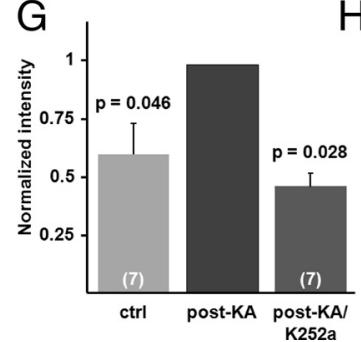

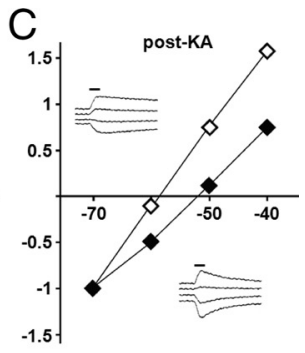

$\mathrm{H}$



Figure 3. A brief period of kainate-induced activity in vitro activates a furosemide-sensitive $\mathrm{Cl}^{-}$extrusion mechanism. $\boldsymbol{A}$, Specimen recordings of field-potential activity induced by kainate in the CA3 region. The right part of the recordings starts at the beginning of the 10 min application of kainate (KA). The activity pattern was similar in slices exposed to kainate (upper trace) and in slices pre-exposed to K252a followed by combined exposure to kainate and K252a (lower trace). $\boldsymbol{B}-\boldsymbol{E}$, In neurons with an artificially imposed somatic $\mathrm{Cl}^{-}$load, whole-cell patch-clamp recordings of $\mathrm{GABA}_{\mathrm{A}}$-mediated currents $\left(\mathrm{I}_{\mathrm{GABA}}\right)$ and $\mathrm{E}_{\mathrm{GABA}}$ in $\mathrm{CA1}$ pyramidal neurons showed a robust imposed $\Delta \mathrm{E}_{G A B A}$ in slices of $P 5-7$ rats pre-exposed to kainate ( $10 \mathrm{~min}, 300 \mathrm{~nm}$; post-KA). The shift in the imposed $\Delta \mathrm{E}_{\mathrm{GABA}}$ was sensitive to furosemide (furo). $\boldsymbol{B}, \boldsymbol{C}$, Sample recordings of uncaging-induced $\mathrm{I}_{\mathrm{GABA}}$ at the soma and at a distance of $50 \mu \mathrm{m}$ in the apical dendrite. I-V curves based on $\mathrm{I}_{\mathrm{GABA}}$ normalized to the peak amplitude at the most negative holding potential $\left(\mathrm{V}_{\mathrm{h}}\right)$ under control conditions $(\boldsymbol{B})$ and after kainate-induced activity $(\boldsymbol{C})$. $\boldsymbol{D}$, The increase in the imposed $\Delta \mathrm{E}_{\mathrm{GABA}}$ after a brief period of kainate-induced activity developed rapidly. Lines connect $\Delta \mathrm{E}_{\mathrm{GABA}}$ values from a given slice. The imposed $\Delta \mathrm{E}_{\mathrm{GABA}}$ did not change when the kainate preincubation was performed in the presence of TTX. $E$, The mean values demonstrated a steep imposed $\Delta \mathrm{E}_{\mathrm{GABA}}$ after the 10 min period of enhanced activity. The increase in the imposed $\Delta \mathrm{E}_{\mathrm{GABA}}$ after kainate application was sensitive to furosemide ( $1 \mathrm{~mm} ; p=0.95$ when compared with control). When the kainate preincubation was performed in the presence of TTX, the imposed $\Delta \mathrm{E}_{\mathrm{GABA}}$ did not differ from the control value $(p=0.70)$, nor did it differ when slices were exposed to kainate in the continuous presence of $\mathrm{K} 252 \mathrm{a}(p=0.30)$. $\boldsymbol{F}$, Biotinylation experiments demonstrated an increase in the surface expression in the CA1 area of P5-7 post-kainate injection slices seen as an increase in the KCC2-IR in the biotinylated fraction. The surface expression of KCC2 was lower in slices exposed to kainate in the continuous presence of K252a compared with slices exposed to kainate. The intensity of the TfR-IR in the biotinylated fraction was not affected by the kainate-induced activity. G, The mean values showed significant differences in the surface expression of KCC2 between control and post-kainate injection slices and between post-kainate and post-kainate plus K252a injection slices. $\boldsymbol{H}$, The presence of the dynamin inhibitory peptide (DIP) in the patch pipette solution in whole-cell patch-clamp recordings of $\mathrm{GABA}_{A}$-mediated currents under an artificial somatic $\mathrm{Cl}^{-}$load led to a significant increase in the imposed $\Delta \mathrm{E}_{\mathrm{GABA}}$. The values for $n$ are shown in brackets.

$\Delta \mathrm{E}_{\mathrm{GABA}}$ was significantly increased by the DIP after 10-30 min from the start of the recording (Fig. $3 \mathrm{H})(2.84 \pm 0.27 \mathrm{mV} / 50 \mu \mathrm{m}$ and $5.76 \pm 1.05 \mathrm{mV} / 50 \mu \mathrm{m}$ for control and DIP, with $n=5$ neurons, 5 slices, 5 animals and $n=5$ neurons, 4 slices, 3 animals, respectively; $p=0.014)$.

\section{Discussion}

The gradual increase in KCC2 expression during the maturation of cortical neurons has often been considered as an explanation of the parallel and gradual developmental $\mathrm{E}_{\mathrm{GABA}}$ shift (for review, see Ben-Ari et al., 2007; Blaesse et al., 2009). An important general conclusion from the present work is that immature hippocampal neurons are capable of undergoing a large precocious negative shift in $\mathrm{E}_{\mathrm{GABA}}$, based on a more efficacious utilization of their low total KCC2 levels. The conclusion is based on our present finding that a single neonatal seizure episode triggers a fast increase in $\mathrm{Cl}^{-}$extrusion, which leads to a large hyperpolarizing shift in $\mathrm{E}_{\mathrm{GABA}}$ and to the development of a native somatodendritic $\mathrm{E}_{\mathrm{GABA}}$ gradient in rat hippocampal CA1 pyramidal neurons at P5-7. The postseizure value of $\mathrm{E}_{\mathrm{GABA}}$ is close to that seen in mature neurons. Notably, an approximately twofold activity-dependent increase in the plasmalemmal protein pool with no change in total KCC2 protein was observed by two different biochemical approaches, biotinylation and cleavage of surface proteins. The increase in surface KCC2 may not fully account for the increase in $\mathrm{Cl}^{-}$extrusion efficacy as additional changes in the intrinsic turnover rate of the transporter might take place in parallel, but it is likely to make a significant contribution to the functional effects observed presently. That fast changes in membrane trafficking of KCC2 have a major effect on $\mathrm{K}-\mathrm{Cl}$ cotransport gained further support from the result that inhibiting endocytosis in a single neuron by adding the endocytosis blocker DIP to the patch pipette led to an increase in the $\mathrm{Cl}^{-}$extrusion capacity. However, fast posttranslational effects such as those described in the present work do not, of course, exclude long-term effects based on enhanced KCC2 protein synthesis. Indeed, the recent work by Galanopoulou (2008) on a similar neonatal seizure model demonstrated an increase in KCC2 expression and activation of KCC2 in male rat pups, which apparently took place after the initial posttranslational effect described in the present work.

In view of the tight functional and structural coupling of KCC2 and the $\alpha 2$ subunit of the Na-K-ATPase (Ikeda et al., 2004), it is interesting that the upregulation of the membrane expression of KCC2 was paralleled by a quantitatively similar upregulation of the Na-K-ATPase which ultimately provides the energy for $\mathrm{K}-\mathrm{Cl}$ cotransporters, including both KCC2a and KCC2b. The available data indicate that the latter isoform is required for the developmental $\mathrm{E}_{\mathrm{GABA}}$ shift, but little is known about the functional significance of KCC2a (Uvarov et al., 2007, 2009). Nevertheless, the parallel activitydependent upregulation of the two isoforms is interesting because of their capability of heterodimerization (Uvarov et al., 2009). 
Any extrapolation from an in vitro model with seizure-like activity to the in vivo model of neonatal seizures should be done with caution. However, the similarities we found between our in vivo and in vitro models (i.e., a fast increase in the $\mathrm{Cl}^{-}$extrusion capacity paralleled by an increase in the surface expression of KCC2) are consistent with the idea that the two models share common underlying molecular mechanisms.

A previous study showed that K252a blocks the seizureinduced downregulation of KCC2 in mature neurons (Rivera et al., 2004). In contrast, we observed presently that K252a blocks the activation of KCC2 induced by seizure-like activity in immature neurons. Similar age-dependent and qualitatively opposite effects have been described for the action of BDNF/TrkB signaling on $\mathrm{GABA}_{\mathrm{A}}$ currents, which are potentiated by BDNF in immature and suppressed in mature neurons (Mizoguchi et al., 2003). Based on the K252a effect in vitro, TrkB is a promising candidate mediating the activation of KCC2 in vivo.

An interesting hypothesis inspired by the present data is that the seizure-induced activation of KCC2 leading to precocious hyperpolarizing $\mathrm{GABA}_{\mathrm{A}}$ responses is an intrinsic fast-acting antiepileptogenic mechanism. The TrkB-mediated increase in $\mathrm{GABA}_{\mathrm{A}}$ receptor-mediated currents (Mizoguchi et al., 2003) may act in parallel to boost the efficacy of inhibition. In addition, further work should address the question of whether activitydependent changes contribute to the fine-tuning of $\mathrm{E}_{\mathrm{GABA}}$ under conditions that are not pathophysiological. Posttranslational mechanisms acting on KCC2 and thereby promoting neuronal plasticity have been described in mature neurons (Vale et al., 2003; Woodin et al., 2003; Rivera et al., 2004; Fiumelli et al., 2005; Wake et al., 2007; Banke and Gegelashvili, 2008), and an exciting topic for future work is to examine whether similar mechanisms operate during hippocampal development.

\section{References}

Balakrishnan V, Becker M, Löhrke S, Nothwang HG, Güresir E, Friauf E (2003) Expression and function of chloride transporters during development of inhibitory neurotransmission in the auditory brainstem. J Neurosci 23:4134-4145.

Banke TG, Gegelashvili G (2008) Tonic activation of group I mGluRs modulates inhibitory synaptic strength by regulating KCC2 activity. J Physiol 586:4925-4934.

Barry PH (1994) JPCalc, a software package for calculating liquid junction potential corrections in patch-clamp, intracellular, epithelial and bilayer measurements and for correcting junction potential measurements. J Neurosci Methods 51:107-116.

Ben-Ari Y, Holmes GL (2006) Effects of seizures on developmental processes in the immature brain. Lancet Neurol 5:1055-1063.

Ben-Ari Y, Gaiarsa JL, Tyzio R, Khazipov R (2007) GABA: a pioneer transmitter that excites immature neurons and generates primitive oscillations. Physiol Rev 87:1215-1284.

Blaesse P, Guillemin I, Schindler J, Schweizer M, Delpire E, Khiroug L, Friauf E, Nothwang HG (2006) Oligomerization of KCC2 correlates with development of inhibitory neurotransmission. J Neurosci 26:10407-10419.

Blaesse P, Airaksinen MS, Rivera C, Kaila K (2009) Cation-chloride cotransporters and neuronal function. Neuron 61:820-838.

De Koninck Y (2007) Altered chloride homeostasis in neurological disorders: a new target. Curr Opin Pharmacol 7:93-99.

Fiumelli H, Cancedda L, Poo MM (2005) Modulation of GABAergic transmission by activity via postsynaptic $\mathrm{Ca} 2+$-dependent regulation of KCC2 function. Neuron 48:773-786.

Galanopoulou AS (2008) Dissociated gender-specific effects of recurrent seizures on GABA signaling in CA1 pyramidal neurons: role of GABAA receptors. J Neurosci 28:1557-1567.

Galanopoulou AS, Vidaurre J, Moshé SL (2002) Under what circumstances can seizures produce hippocampal injury: evidence for age-specific effects. Dev Neurosci 24:355-363.

Glykys J, Dzhala VI, Kuchibhotla KV, Feng G, Kuner T, Augustine G, Bacskai
BJ, Staley KJ (2009) Differences in cortical versus subcortical GABAergic signaling: a candidate mechanism of electroclinical uncoupling of neonatal seizures. Neuron 63:657-672.

Grosshans DR, Clayton DA, Coultrap SJ, Browning MD (2002) LTP leads to rapid surface expression of NMDA but not AMPA receptors in adult rat CA1. Nat Neurosci 5:27-33.

Hall RA, Soderling TR (1997) Differential surface expression and phosphorylation of the N-methyl-D-aspartate receptor subunits NR1 and NR2 in cultured hippocampal neurons. J Biol Chem 272:4135-4140.

He S, Ma J, Liu N, Yu X (2010) Early enriched environment promotes neonatal GABAergic neurotransmission and accelerates synapse maturation. J Neurosci 30:7910-7916.

Hewitt SA, Wamsteeker JI, Kurz EU, Bains JS (2009) Altered chloride homeostasis removes synaptic inhibitory constraint of the stress axis. Nat Neurosci 12:438-443.

Huberfeld G, Wittner L, Clemenceau S, Baulac M, Kaila K, Miles R, Rivera C (2007) Perturbed chloride homeostasis and GABAergic signaling in human temporal lobe epilepsy. J Neurosci 27:9866-9873.

Hübner CA, Stein V, Hermans-Borgmeyer I, Meyer T, Ballanyi K, Jentsch TJ (2001) Disruption of KCC2 reveals an essential role of K-Cl cotransport already in early synaptic inhibition. Neuron 30:515-524.

Ikeda K, Onimaru H, Yamada J, Inoue K, Ueno S, Onaka T, Toyoda H, Arata A, Ishikawa TO, Taketo MM, Fukuda A, Kawakami K (2004) Malfunction of respiratory-related neuronal activity in $\mathrm{Na}^{+}, \mathrm{K}^{+}$-ATPase $\alpha 2$ subunit-deficient mice is attributable to abnormal $\mathrm{Cl}^{-}$homeostasis in brainstem neurons. J Neurosci 24:10693-10701.

Kahle KT, Staley KJ, Nahed BV, Gamba G, Hebert SC, Lifton RP, Mount DB (2008) Roles of the cation-chloride cotransporters in neurological disease. Nat Clin Pract Neurol 4:490-503.

Khalilov I, Holmes GL, Ben-Ari Y (2003) In vitro formation of a secondary epileptogenic mirror focus by interhippocampal propagation of seizures. Nat Neurosci 6:1079-1085.

Khirug S, Huttu K, Ludwig A, Smirnov S, Voipio J, Rivera C, Kaila K, Khiroug L (2005) Distinct properties of functional KCC2 expression in immature mouse hippocampal neurons in culture and in acute slices. Eur J Neurosci 21:899-904.

Khirug S, Yamada J, Afzalov R, Voipio J, Khiroug L, Kaila K (2008) GABAergic depolarization of the axon initial segment in cortical principal neurons is caused by the $\mathrm{Na}-\mathrm{K}-2 \mathrm{Cl}$ cotransporter NKCC1. J Neurosci 28:4635-4639.

Kim Y, Trussell LO (2007) lon channels generating complex spikes in cartwheel cells of the dorsal cochlear nucleus. J Neurophysiol 97:1705-1725.

Lee FS, Chao MV (2001) Activation of Trk neurotrophin receptors in the absence of neurotrophins. Proc Natl Acad Sci U S A 98:3555-3560.

Lee HH, Walker JA, Williams JR, Goodier RJ, Payne JA, Moss SJ (2007) Direct protein kinase C-dependent phosphorylation regulates the cell surface stability and activity of the potassium chloride cotransporter KCC2. J Biol Chem 282:29777-29784.

Ludwig A, Li H, Saarma M, Kaila K, Rivera C (2003) Developmental upregulation of KCC2 in the absence of GABAergic and glutamatergic transmission. Eur J Neurosci 18:3199-3206.

Mizoguchi Y, Ishibashi H, Nabekura J (2003) The action of BDNF on GABAA currents changes from potentiating to suppressing during maturation of rat hippocampal CA1 pyramidal neurons. J Physiol 548:703-709.

Muñoz A, Méndez P, DeFelipe J, Alvarez-Leefmans FJ (2007) Cationchloride cotransporters and GABA-ergic innervation in the human epileptic hippocampus. Epilepsia 48:663-673.

Payne JA (1997) Functional characterization of the neuronal-specific K-Cl cotransporter: implications for $[\mathrm{K}+](\mathrm{o})$ regulation. Am J Physiol 273:C1516-C1525.

Rennie J, Boylan G (2007) Treatment of neonatal seizures. Arch Dis Child Fetal Neonatal Ed 92:F148-F150.

Rivera C, Voipio J, Thomas-Crusells J, Li H, Emri Z, Sipilä S, Payne JA, Minichiello L, Saarma M, Kaila K (2004) Mechanism of activitydependent downregulation of the neuron-specific $\mathrm{K}-\mathrm{Cl}$ cotransporter KCC2. J Neurosci 24:4683-4691.

Russell JM (2000) Sodium-potassium-chloride cotransport. Physiol Rev 80:211-276.

Ruusuvuori E, Li H, Huttu K, Palva JM, Smirnov S, Rivera C, Kaila K, Voipio J (2004) Carbonic anhydrase isoform VII acts as a molecular switch in 
the development of synchronous gamma-frequency firing of hippocampal CA1 pyramidal cells. J Neurosci 24:2699-2707.

Sipilä ST, Schuchmann S, Voipio J, Yamada J, Kaila K (2006) The cationchloride cotransporter NKCC1 promotes sharp waves in the neonatal rat hippocampus. J Physiol 573:765-773.

Sipilä ST, Huttu K, Yamada J, Afzalov R, Voipio J, Blaesse P, Kaila K (2009) Compensatory enhancement of intrinsic spiking upon NKCC1 disruption in neonatal hippocampus. J Neurosci 29:6982-6988.

Uvarov P, Ludwig A, Markkanen M, Pruunsild P, Kaila K, Delpire E, Timmusk T, Rivera C, Airaksinen MS (2007) A novel N-terminal isoform of the neuron-specific K-Cl cotransporter KCC2. J Biol Chem 282:3057030576.

Uvarov P, Ludwig A, Markkanen M, Soni S, Hübner CA, Rivera C, Airaksinen MS (2009) Coexpression and heteromerization of two neuronal $\mathrm{K}-\mathrm{Cl}$ cotransporter isoforms in neonatal brain. J Biol Chem 284:13696-13704.

Vale C, Schoorlemmer J, Sanes DH (2003) Deafness disrupts chloride transporter function and inhibitory synaptic transmission. J Neurosci 23:7516-7524.

Wake H, Watanabe M, Moorhouse AJ, Kanematsu T, Horibe S, Matsukawa N, Asai K, Ojika K, Hirata M, Nabekura J (2007) Early changes in KCC2 phosphorylation in response to neuronal stress result in functional downregulation. J Neurosci 27:1642-1650.

Wigge P, McMahon HT (1998) The amphiphysin family of proteins and their role in endocytosis at the synapse. Trends Neurosci 21:339-344.

Woodin MA, Ganguly K, Poo MM (2003) Coincident pre- and postsynaptic activity modifies GABAergic synapses by postsynaptic changes in $\mathrm{Cl}-$ transporter activity. Neuron 39:807-820. 